American Journal of Applied Sciences 9 (1): 83-88, 2012

ISSN 1546-9239

(C) 2012 Science Publications

\title{
Digital Simulation, Design, Comparitive Analysis of Intelligent Controllers in Adjustable Speed Drives for PQ Enhancement
}

\author{
A. Srikrishnan and B. Justus Rabi \\ Department of Electronics and Communication Engineering, \\ Dr. MGR University, Chennai-95, India
}

\begin{abstract}
Problem statement: This study deals with the analysis, design and comparison between fuzzy and genetic based adjustable speed drives with respect to the parameters which determines the quality of power. Approach: ASD system using fuzzy controllers provide ride-through capability during voltage sags, reduces harmonics, improves power factor and is highly reliable, whereas by using genetic algorithm optimized ASD systems, the harmonic contents and distortion factor are fairly less and the power factor approaches unity. A feasible test is implemented by building a proto-type intelligent ASD, which is designed and controlled on the basis of proposed considerations. It is verified from the practical point of view that both the new approaches are more effective and acceptable to minimize the harmonic distortion and improve the quality of power. Results: Thus GA's performance outscores over fuzzy in all power quality parameter measures and the proposed optimizing strategies can be applied to any variable-frequency DC-AC inverters, UPSs and ac drives. Conclusion: Finally, it is deduced that GA is the most efficient methodology to improve the power quality of the adjustable speed drives.
\end{abstract}

Key words: Total Harmonic Distortion (THD), Pulse Width Modulation (PWM), Distortion Factor (DF), Adjustable Speed Drives (ASD), Fuzzy Logic Control (FLC), Genetic Algorithm (GA)

\section{INTRODUCTION}

In the development of science and technology, various power electronics equipment with PWM Inverters are being used in Industrial applications, power network systems and their constant usage like ASDs, UPSs and Variable Frequency Drives have caused significant inherent problems (Routimo et al., 2005), such as generation of reactive current and power as well as higher harmonic distortion in the utility power sources. The traditional drives consist of Voltage Source Inverter (VSI) or Current Source Inverter (CSI), both of which comprise of a front end diode rectifier, dc link and Inverter Bridge. To boost power factor, either an ac inductor or dc inductor is normally used. The dc link voltage is 1.35 times of line voltage and the voltage source inverter is a buck inverter that produces ac voltage limited by the dc link. Therefore VSI and CSI are characterized by relatively low efficiency because of switching losses and considerable EMI generation (Inzunza and Akagi, 2006). Therefore it is necessary and advantageous to have a complete ASD system that uses an efficient method to suppress the harmonic distortion. In this study, a method based on Fuzzy Logic Control and GA is proposed to suppress the harmonic distortion. Compared with the techniques of Standard PWM and Random PWM, the proposed strategies has smaller harmonic distortion, has a harmonic energy spread resulting in less loss and lower acoustic noise. ASD system suffers from the limitation of less output voltage than the input line voltage.

The diode rectifier fed by the $415-\mathrm{V}$ ac line produces about $560-\mathrm{V}$ dc on the dc-link, which is roughly 1.35 times the line-to-line input voltage under the assumption of heavy load and continuous " doublehump" input current for large ( $>50 \mathrm{~kW})$ drives that have an approximate value of $3 \%$ inductance on the ac or dc side. For light load operation or small drives with no significant inductance, the line current becomes discontinuous "double-pulse," and the dc voltage is closer to 1.41 times the line-to-line input voltage $400 \mathrm{~V}$ motor, the low obtainable output voltage significantly limits output power that is proportional to the square of the voltage (Liserre et al., 2004). This is a very undesirable situation for many applications because the motor and drive system has to be oversized for a required power. Voltage sags can interrupt an ASD system and shut down critical loads and processes (Rabi et al., 2007). Over $90 \%$ of power quality related problems are from momentary (typically $0.1-2 \mathrm{~s}$ )

Corresponding Author: A. Srikrishnan, Department of Electronics and Communication Engineering, Dr. MGR University, Chennai-95, India 
voltage sags of $10-50 \%$ below nominal value. The dc capacitor in drives is a relatively small energy storage element, which cannot hold dc voltage above the operable level under such voltage sags (Rabi, 2006). The standard options involve providing a fly back converter or boost converter with energy storage or diode rectifier to achieve ride-through of parameters of power; however, these options come with cost penalty, size/weight and complexity. Inrush and harmonic current from the diode rectifier can pollute the line voltage and current (Ozpineci et al., 2005).

\section{MATERIALS AND METHODS}

In this study, the analysis is done by simulation and experimental studies on ASD with various output strategies. Performance and reliability are compromised by the traditional drive structure, because miss-gating from EMI can cause shoot-through that leads to destruction of the inverter, the dead time that is needed to avoid shoot-through creates distortion, low power factor, unstable operation at low speeds and commonmode voltage causes shaft current and premature failures of the motor.

Fuzzy based ASD system: The basic configuration of a fuzzy logic controller as shown in Fig. 1 comprises of four principle components:

- Fuzzification interface

- Knowledge base

- Decision making logic

- Defuzzification interface

The first stage in all FLCs is the fuzzification of inputs. The proposed FLC takes error and change in error of the output state as inputs. FLC with triangular input and output membership functions can be expressed as a Fuzzy Associative Memory (FAM).The heart of an FLC is the rule/knowledge base represented by FAM, as shown in Table 1. Digital implementations is done through digital to analog conversion process.

Fuzzy rules and inferences: For fuzzy logic control, a few more concepts such as fuzzy implication (fuzzy rules) and fuzzy composition (fuzzy inference) are important. A fuzzy rule typically has an IF-THEN format.

IF ( $x$ is A AND y is B) then $z$ is $C$ where, $x, y$ and $\mathrm{z}$ are fuzzy variables and $\mathrm{A}, \mathrm{B}$ and $\mathrm{C}$ are fuzzy subsets in the universe of discourse $\mathrm{X}, \mathrm{Y}$ and $\mathrm{Z}$ respectively (Sharmeela et al., 2007). If the conditions expressed in the 'IF' portion are met, then the action specified in the 'THEN' portion are taken. In order to design a fuzzy controller a fuzzy rule base consisting of several rules must be constructed. Figure $2 \mathrm{a}$ and $\mathrm{b}$ shows the membership function input and output respectively.

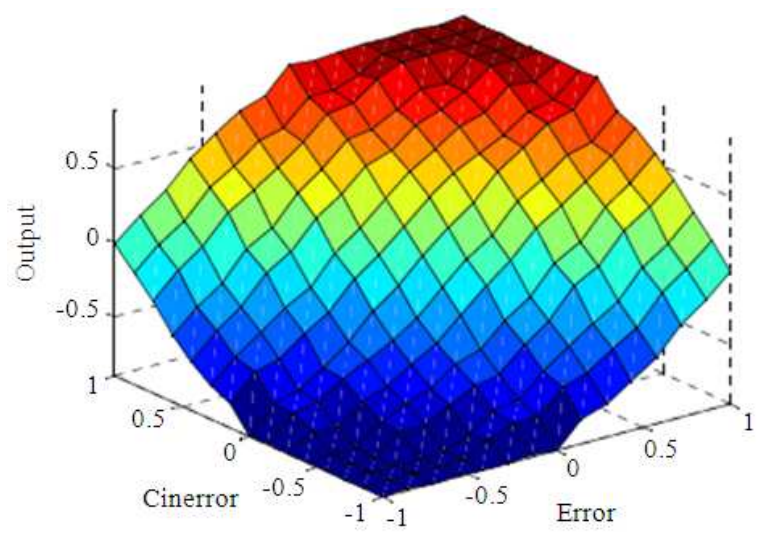

Fig. 1: Surface Plot between two inputs (error and change in error)

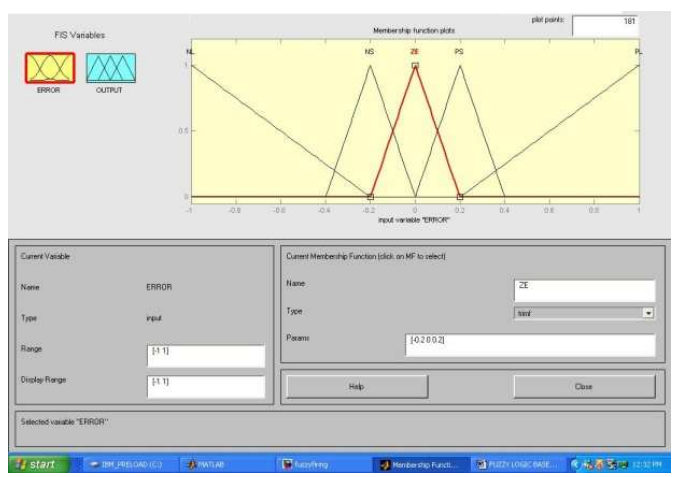

(a)

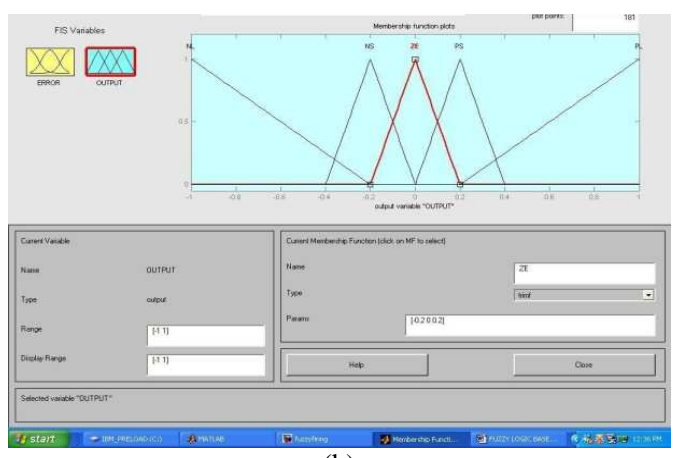

(b)

Fig. 2: (a) Membership function input (b) Membership function output

Intuition method is used for assignment of membership functions (Leon et al., 2009). It is derived from the capacity of humans to develop membership through their own innate intelligence and understanding. Intuition involves contextual and semantic knowledge about an issue it can also involve truth values about this knowledge. 
Am. J. Applied Sci., 9 (1): 83-88, 2012

Table 1: Fuzzy associative memory table

\begin{tabular}{llllllll}
\hline e/ce & NB & NM & NS & NE & PS & PM & PB \\
\hline NB & NB & NB & NB & NB & NM & NS & ZE \\
NM & NB & NB & NB & NM & NS & NE & PS \\
NS & NB & NB & NM & NS & NE & PS & PM \\
ZE & NB & NM & NS & ZE & PS & PM & PB \\
PS & NM & NS & ZE & PS & PM & PB & PB \\
PM & NS & ZE & PS & PM & PB & PB & PB \\
PB & ZE & PS & PM & PB & PB & PB & PB \\
\hline
\end{tabular}

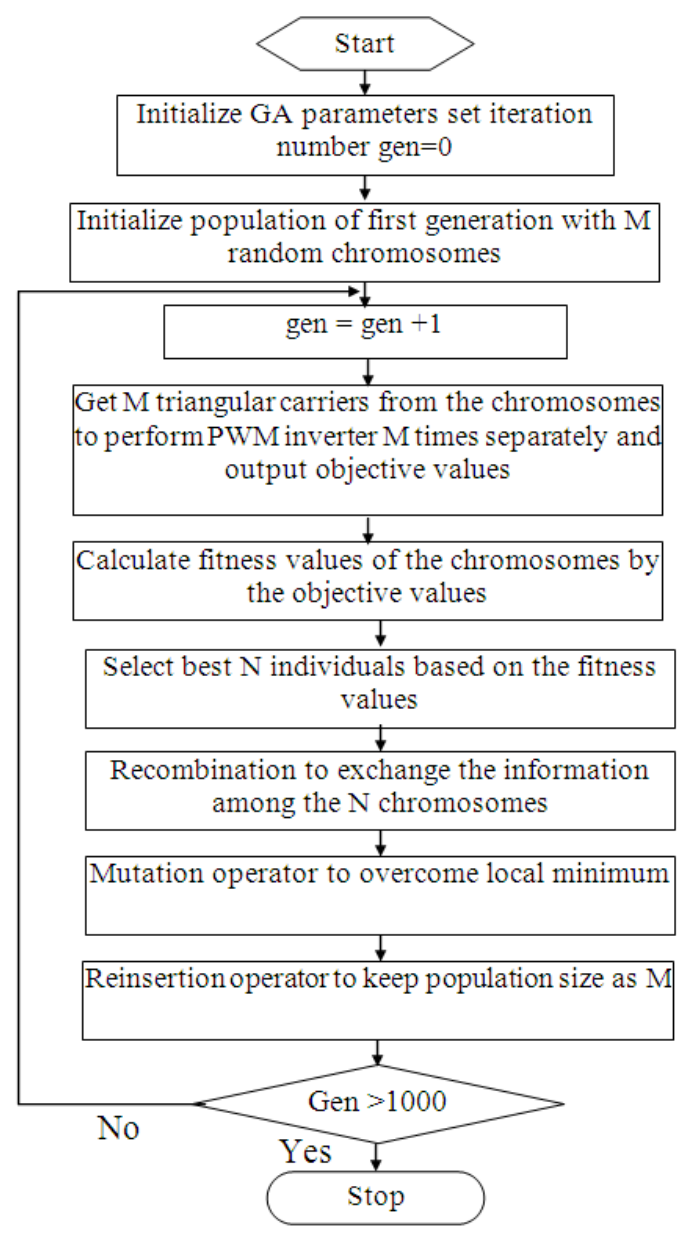

Fig. 3: GA operation flowcharts

GA optimsed ASD system: GAs has recently been applied to optimize electrical drive systems. In order to find the best triangular carrier sequence for a DSP based sinusoidal PWM inverter, real-valued GA is employed with minimum harmonic distortion as the objective function. In a GA, the objective function is used to provide a measure of performance valuation. For the proposed optimized PWM inverter, the GA procedure should be consisting of the following operations:

- $\quad$ Performance evaluating
- Fitness calculation

- Selection

- Recombination (crossover)

- Mutation

- Reinsertion

The Genetic Algorithm uses objective functions based on some performance criterion to calculate an error (Ozpineci et al., 2005). However, the Genetic Algorithm is based on natural selection using random numbers and does not require a good initial estimate. Genetic algorithms manipulate strings of binary digits and measure each string's strength with a fitness value. The stronger strings advance and mate with other strong strings to produce offspring. Eventually, one string emerges as the best. One of the most important advantages of the Genetic Algorithm over the NewtonRaphson technique is that it is able to find the global minimum, instead of a local minimum and that the initial estimate need not be close to the actual values. Another advantage is that it does not require the use of the derivative of the function, which is not always easily obtainable or may not even exist, for example, when dealing with real measurements involving noisy data. Figure 3 give the flowchart for GA operation.

Reproduction is a process in which individual strings are selected according to their fitness. The fitness is determined by calculating how well each string fits an objective function. Copying strings according to their fitness value implies that strings that fit the objective function well have a higher probability of contributing one or more offspring in the next generation. This process of reproduction is, of course, an artificial version of natural selection.

Crossover is a two-step process that involves mating and swapping of partial strings. Each time the crossover operator takes action; two randomly selected strings from the mating pool are mated. Then, in the case of simple crossover, a position along one string is selected at random and all binary digits following the position are swapped with the second string. The result is two entirely new strings that move on to the next generation.

Mutation follows crossover and protects against the loss of useful genetic information (1's and 0's). The operator works by randomly selecting one string and one bit location and changing that string's bit from a 1 to a 0 or vice versa. The probability for mutation to occur is usually very small, roughly one mutation per 1000 bit transfers. The three genetic operators, reproduction, crossover and mutation, provide an effective search technique using natural selection and random number generation. Advanced operators, such as dominance, inversion and segregation exist, but are generally not essential for good results to many problems. 


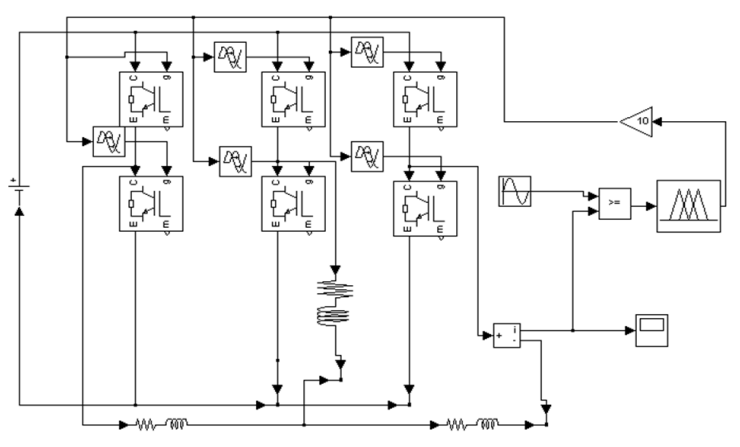

Fig. 4: Simulink realization

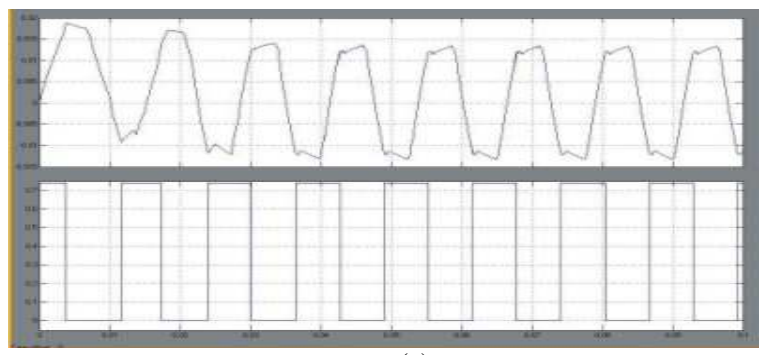

(a)

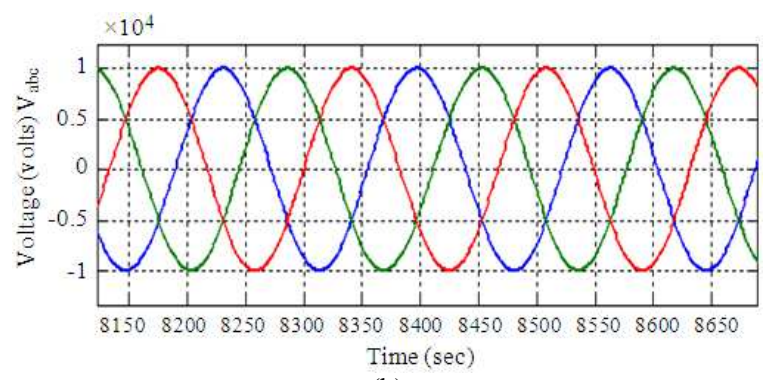

(b)

Fig. 5: (a) Gate pulses (b) Simulated output voltage

Simulation of proposed strategies: In some cases, the advanced operators can degrade the performance of the genetic algorithm. This study explains the real-valued GA performed on an offline PC with Matlab software. The simulink realization of the proposed system is shown in Fig. 4.With gradient convergence processing, the THD of the PWM inverter output voltage is reduced about 5\% (from 0.9141-0.8715) at the 500th generation and the optimized carrier sequence is yielded. In order to compare it with other PWM strategies, the averaged value of harmonic distortions of the random PWM is calculated by Eq. 1-3:

$$
\text { ATHD }=\frac{\sum_{\mathrm{i}=1}^{\mathrm{M}} \mathrm{THD}(\mathrm{i})}{\mathrm{M}}
$$

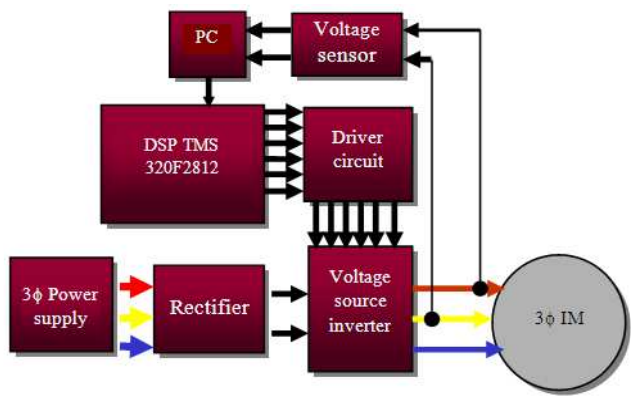

(a)

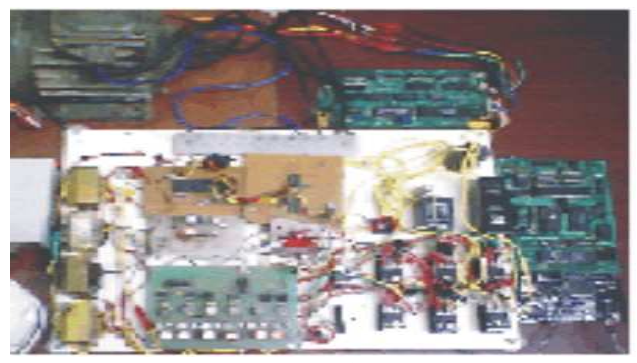

(b)

Fig. 6: (a) Block diagram of experimental set-up (b) Experimental setup

AWTHD $=\frac{\sum_{i=1}^{M} \text { WTHD(i) }}{M}$

$\mathrm{ADF}=\frac{\sum_{\mathrm{i}=1}^{\mathrm{M}} \mathrm{DF}(\mathrm{i})}{\mathrm{M}}$

where, ATHD is the average value of THD, AWTHD is the average value of WTHD and ADF is the average value of $\mathrm{DF}$ in $\mathrm{M}$ sinusoidal cycles. In this letter, $\mathrm{M}=$ 500. Applying the GA to different carrier frequencies, the corresponding optimized PWM carrier sequences are obtained that the GA-optimized PWM strategy not only spreads harmonic energy, but also achieves the best THD (reduced about 5\%) compared with other PWM strategies at different carrier frequencies. If WTHD is selected as the optimized target, the GAoptimized PWM strategy has better WTHD than other PWM strategies but the improvement is not significant when the switching frequency is higher than $5 \mathrm{kHz}$. If DF is used as the optimized target, the GA-optimized PWM strategy also has the best DF compared to other PWM strategies.

Hardware implementation: The gate pulses and the simulated output voltage are shown in Fig. 5a and 5b respectively. The block diagram and main circuit configuration of intelligent ASD system with fuzzy control harmonics level is shown in Fig. 6a and 6b respectively. 
This circuit consists of a three-phase inverter using MOSFETs. The triggering pulses from FLC are used to control and suppress harmonic distortion. Phase currents are measured and compared with a reference and error signal is fuzzified. The triangular membership function is assigned. If-THEN rules are trained for control purpose. The triangular method is used for defuzzification.

\section{RESULTS}

The inverter modulation index was 1.0 , producing the same DPWM waveform $\left(\mathrm{VI}_{\mathrm{ab}}\right)$ as the traditional inverter. However, the magnitude of the output voltage was boosted to $415 \mathrm{~V} \mathrm{rms}$ and was confirmed by the sinusoidal waveform $\left(\mathrm{V}_{\mathrm{Lab}}\right)$. The traditional PWM inverter cannot produce $400 \mathrm{~V}$ rms output voltage. The boost factor B was 1.21. Also, it is noted that the line current contains negligible harmonics than the traditional ASD system without dc inductors and appreciably less harmonics that the traditional ASD system even with dc inductor. Again, the line current harmonics have been reduced greatly.

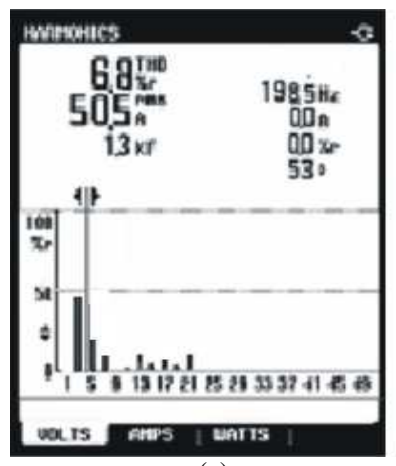

(a)

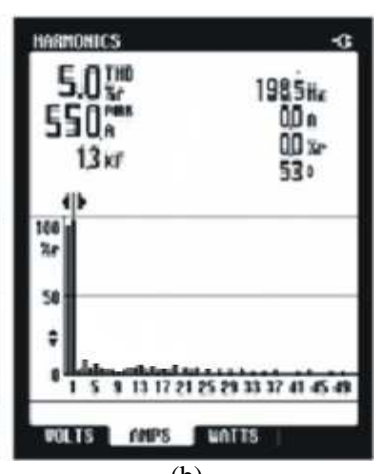

(b)
Fig. 7: Harmonic analyzer outputs FLC based ASD system (a) Voltage Harmonics (b) Current Harmonics

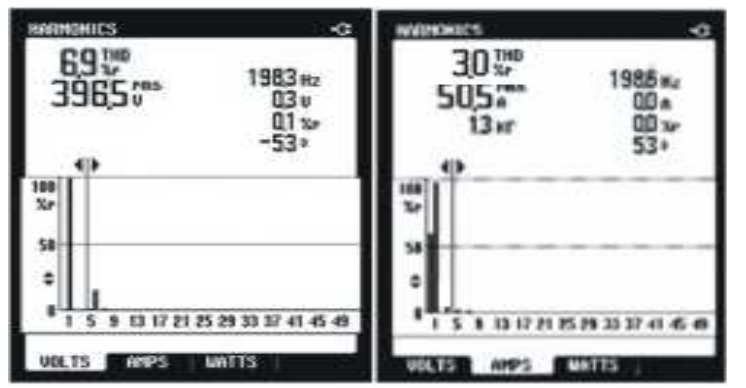

(a)

(b)

Fig. 8: Harmonic analyzer outputs Genetic Algorithm based ASD system (a) Voltage Harmonics (b) Current Harmonics
A prototype has been built to further verify the operation; the critical relationships of voltage boost and simulation results of the presented FLC based ASD system. It should be noted that the inductors and capacitors were oversized in the prototype for possible regenerative operation during deceleration or inverter trips. For large (50 kW or above) drives a dc inductor is commonly used to minimize line harmonic current and voltage distortionThe experimental facility consists of a FLC board, inverter module, a digital oscilloscope, harmonic analyzer and a set of power supplies. The outputs from the harmonic analyzer using FLC, the voltage and harmonics are shown in Fig. $7 \mathrm{a}$ and $7 \mathrm{~b}$ respectively.

\section{DISCUSSION}

The performance of the proposed Fuzzy logic controller based ASD has been demonstrated experimentally (Darly et al., 2010; Rabi and Arumugam, 2005) and the voltage and current harmonics are shown in Fig. 8a and $8 \mathrm{~b}$ respectively. Similar set-up is used for GA based ASD system. The harmonic analyzer output of the GA optimized ASD is shown in the Fig. 9a and $9 \mathrm{~b}$ respectively.

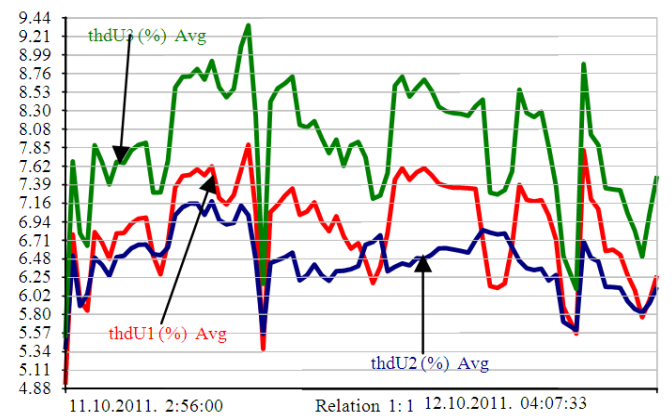

(a)

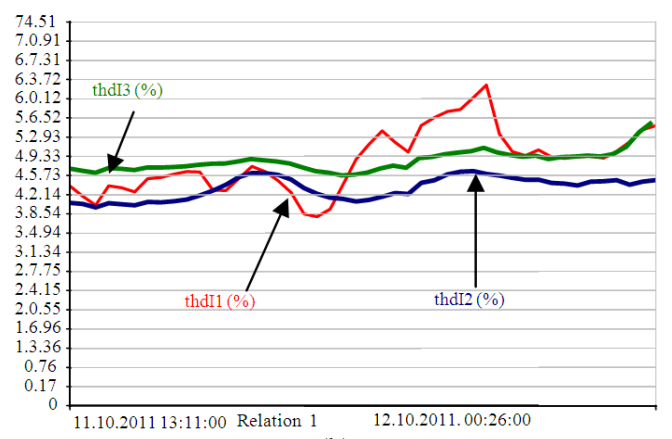

(b)

Fig. 9: Experimental Waveforms FLC based ASD system (a) Voltage Harmonics (b) Current Harmonics 
Am. J. Applied Sci., 9 (1): 83-88, 2012

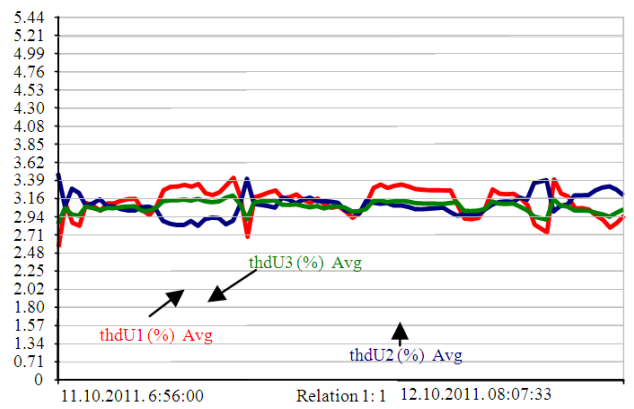

(a)

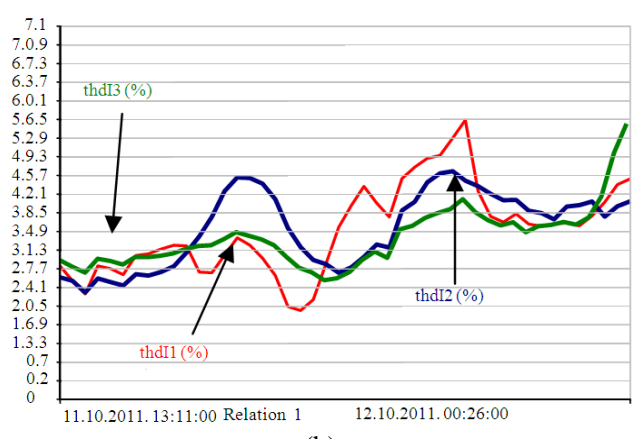

(b)

Fig. 10: Experimental waveforms genetic algorithm based ASD system (a) Voltage harmonics (b) Current harmonics

Experimental Waveforms for Genetic Algorithm based ASD system is shown in Fig. 10. From the Genetic Algorithm Optimized ASD system, the 3rd, 5th, 7th harmonic contents are 10, 15 and 9\% respectively. From the above observations, it is noted that the Total Harmonic Distortion (THD) in GA optimized PWM inverter is less.

\section{CONCLUSION}

This study compares the harmonic reduction method of ASDs that employs the Fuzzy Logic control and Genetic algorithm techniques. Simulation and Experimental Studies have demonstrated that the GA optimized ASD system proves a better power quality solution when compared with the traditional ASD systems and ASDs which employs Fuzzy Logic Control strategy. By comparing the Harmonic Analyzer outputs of FLC based ASD system with that of GA based ASD system, it is clearly shown that by using FLC technique, voltage and current THD were 6.8 and 5.0\% respectively where as the voltage and current THD were 6.9 and $3.0 \%$ using GA based approach and which can produce any desired output ac voltage, even greater than the line voltage, provides ride-through during voltage sags without any additional circuits and energy storage, minimizes the motor ratings to deliver a required power, reduces in-rush and harmonic current.

Unique features of intelligent ASD include buckboost inversion by single power-conversion stage and output waveform with negligible Distortion Factor.

\section{REFERENCES}

Darly, S., R. Vanaja and R.J. Benjamin, 2010. FLC based adjustable speed drives for power quality enhancement. Serbian J. Elect. Eng., 7: 217-229.

Inzunza, R. and H. Akagi, 2006. Design and performance of a transformerless shunt hybrid active filter for installation on a $6.6-\mathrm{kV}$ power distribution system. IEEE Trans. Industry Appli., 126: 497-503.

Leon, J.I., S. Vazquez, A.J. Watson, L.G. Franquelo and P.W. Wheeler et al., 2009. Feed-forward space vector modulation for single-phase multilevel cascaded converters with any DC voltage ratio. IEEE Trans. Ind. Elect., 56: 315-325. DOI: 10.1109/TIE.2008.926777

Liserre, M., A. Dell'Aquila and F. Blaabjerg, 2004. Genetic algorithm-based design of the active damping for an LCL-filter three-phase active rectifier. IEEE Trans. Power Elect., 19: 76-86. DOI: 10.1109/TPEL.2003.820540

Ozpineci, B., L.M. Tolbert and J.N. Chiasson, 2005. Harmonic optimization of multilevel converters using genetic algorithms. IEEE Power Elect. Lett., 3: 92-95. DOI: 10.1109/LPEL.2005.856713

Rabi, B.J. and R. Arumugam, 2005. Harmonics study and comparison of z-source inverter with traditional inverters. Am. J. Applied Sci., 2: 14181426. DOI: 10.3844/ajassp.2005.1418.1426

Rabi, B.J., 2006. Minimization of harmonics in PWM inverters based on genetic algorithms. J. Applied Sci., 6: 2056-2059.

Rabi, B.J., S.S. Darly and R. Arumugam, 2007. Power quality enhancement in ASD systems using genetic algorithms. Iranian J. Elect. Comput. Eng., 6: 119124.

Routimo, M., M. Salo and H. Tuusa, 2005. Comparison of voltage-source and current-source shunt active power filters. Proceedings of the IEEE 36th Power Electronics Specialists Conference, Jun. 16-16, IEEE Xplore Press, Recife, pp: 2571-2577. DOI: 10.1109/PESC.2005.1581995

Sharmeela, C., M.R. Mohan, G. Uma and J. Baskaran, 2007. Fuzzy logic controller based three-phase shunt active filter for line harmonics reduction. J. Comput. Sci., 3: 76-80. DOI: $10.3844 /$ jcssp.2007.76.80 